\title{
CARBON BLACK-POLYETHYLENE COMPOSITES STUDIED BY POSITRON ANNIHILATION
}

\author{
M. Dęrowska ${ }^{a}$, J. Rudzińska-Girulska ${ }^{a}$, A. Pasternak ${ }^{b}$ \\ AND R. POŹNIAK ${ }^{b}$ \\ ${ }^{a}$ Institute of Experimental Physics, Wrocław University \\ Pl. M. Borna 9, 50-204 Wrocław, Poland \\ ${ }^{b}$ Institute of Organic and Polymer Technology, Wroclaw. University of Technology \\ Wybrzeże Wyspiańskiego 27, 50-370 Wrocław, Poland
}

\begin{abstract}
Preliminary results of positron annihilation lifetime measurements, performed for carbon black-LDPE composites with three kinds of carbon black (PRINTEX XE2, VULCAN XC-72, and SAKAP 6) are presented. Four components with lifetimes $\tau_{1} \approx 120 \mathrm{ps}, \tau_{2} \approx 340 \mathrm{ps}, \tau_{3} \approx 1.2 \mathrm{~ns}, \tau_{4} \approx 2.8 \mathrm{~ns}$ occurred to be the best fitted to measured positron lifetime spectra. The presence of carbon black resulted only in reduction of intensities of the components with the lifetimes $\tau_{1}, \tau_{3}, \tau_{4}$ (originating in our opinion from the annihilation of the positronium) and increase in the intensity of the component with the lifetime $\tau_{2}$. The intensities depend both on the content of carbon black and its kind as well. The strongest influence of the carbon black of the highest specific surface area (PRINTEX XE2) has been observed at the intensities which correlate well with the results of studies of resistivity and tensile strength for the same samples.
\end{abstract}

PACS numbers: $71.60 .+\mathrm{z}, 78.70 . \mathrm{Bj}, 82.30 . \mathrm{Hk}$

\section{Introduction}

Carbon black blended with polyethylene makes up a conductive composite, attractive for usage in electrical and electronic devices. It is due to good mechanical properties of the product and the possibility to change easily its resistivity in rather broad interval when changing the carbon black concentration. Properties of the composite are affected by processing conditions, the kind of the polymer and the carbon black being used as well as the content and distribution of the carbon black in the polymer matrix. It is generally known that the highest conductivity and the lowest percolation threshold are achieved when carbon blacks of very high specific surface areas and a large extent of graphitization are used [1].

\section{Materials}

Low density polyethylene (POLITEN II/003/GO) manufactured by Blachownia (Poland) was used as the matrix. Its melt index was $2.9 \mathrm{~g} / 10 \mathrm{~min}$, density $0.922 \mathrm{~g} / \mathrm{cm}^{3}$, degree of crystallinity $38.1 \%$ [2], and melting point was $109^{\circ} \mathrm{C}$. 
PRINTEX XE2 (Degussa Co., Germany), VULCAN XC-72 (Cabot Corp., USA) and SAKAP 6 (Carbochem, Poland) were used as the conducting fillers.

\section{Preparation of composites}

LDPE was first kneaded by a mixing roller for $5 \mathrm{~min}$ and a filler was then added. The mixture was kneaded for $10 \mathrm{~min}$. Kneading temperature was $160-170^{\circ} \mathrm{C}$. The kneaded sample was set in a predetermined mold. The sample was molten for $5 \mathrm{~min}$ at $180^{\circ} \mathrm{C}$ and then pressed in for $10 \mathrm{~min}$ under a pressure of $200 \mathrm{MPa}$. The samples were then cooled to obtain films about $1 \mathrm{~mm}$ thick.

\section{Mechanical properties}

The tensile strength of LDPE and composites containing fillers were determined from measurements performed with the use of an Instron tensile apparatus at room temperature, according to the $\mathrm{PN}-81 / \mathrm{C}-89034$. The drawing speed was $50 \mathrm{~mm} / \mathrm{min}$ and the data were averaged over at least five tests.

The mechanical strength of composites dropped as a result of carbon black addition to polyethylene (Fig. 1). The effect does not depend only on the content of the carbon black but also on its kind. The greatest influence is seen in case of PRINTEX XE2, the filler of the highest specific surface area.

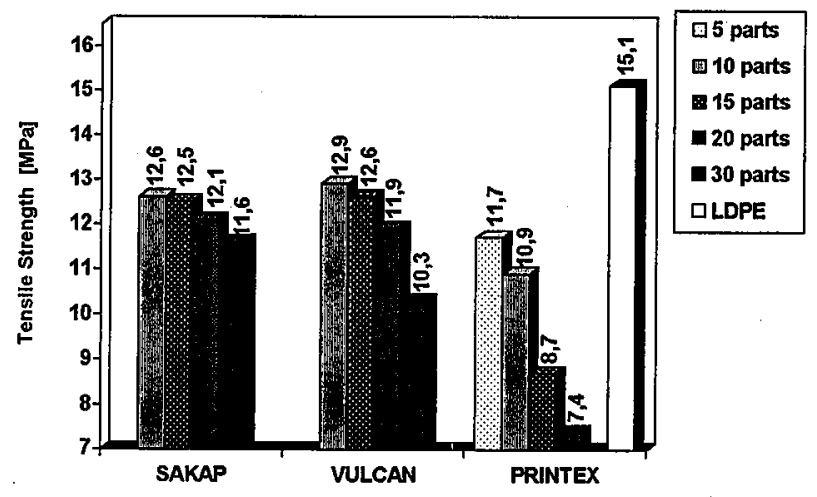

Fig. 1. The tensile strength vs. carbon black content.

\section{Electrical resistivity of composites}

The electrical resistivity of samples was measured at room temperature according to the PN-88/E-04405. The measurements were performed by means of a $\mathrm{dc}$ amplifier and the electrometer Teralin III (Statron, Germany).

It is seen (Fig. 2) that, in general, SAKAP 6 must be used at a significantly higher concentrations than VULCAN XC-72, and VULCAN XC-72 carbon black must be used at a higher concentration than PRINTEX XE2 to attain a given conductivity level. The three curves are of similar shape - very steep at lower concentrations and less steep at-higher ones. It is seen that the conductivity depends on the carbon black content and increases with a rising specific surface area and elevated structure of the incorporated carbon black. 


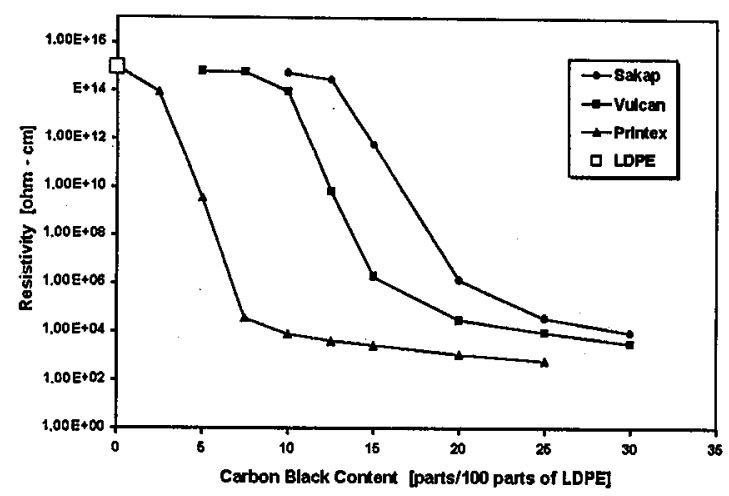

Fig. 2. Surface resistivity vs. carbon black content.

\section{Positron lifetime measurements}

A conventional fast-fast coincidence system with two plastic scintillators of type BC418 (each shaped as a truncated cone of volume equal to $12.9 \mathrm{~cm}^{3}$ and coupled with the RCA 8850 photomultiplier) was used for measuring the lifetime spectra.

The positron source, ${ }^{22} \mathrm{Na}$ of activity $\approx 15 \mu \mathrm{Ci}$ was deposited between two identical thin Hostaphan foils $\left(0.8 \mathrm{mg} \cdot \mathrm{cm}^{-2}\right.$ each) and then sandwiched between the samples $\left(10 \times 10 \times 0.2 \mathrm{~mm}^{3}\right)$ under investigation. A typical decay curve contained about $8 \times 10^{6}$ counts and had the peak to background ratio of $5 \times 10^{3}$.

The PAL spectra, not corrected for positron annihilation in the source, were. best fitted with a sum of four exponential decay functions convoluted with the time-resolution function of the spectrometer (a Gaussian curve with a double-sided exponential) plus a constant background, using the program LT [3]. Intensities and lifetimes are shown in Fig. 3 for the polyethylene composites with SAKAP 6. The trend of changes of intensities and lifetimes is the same for all composites.
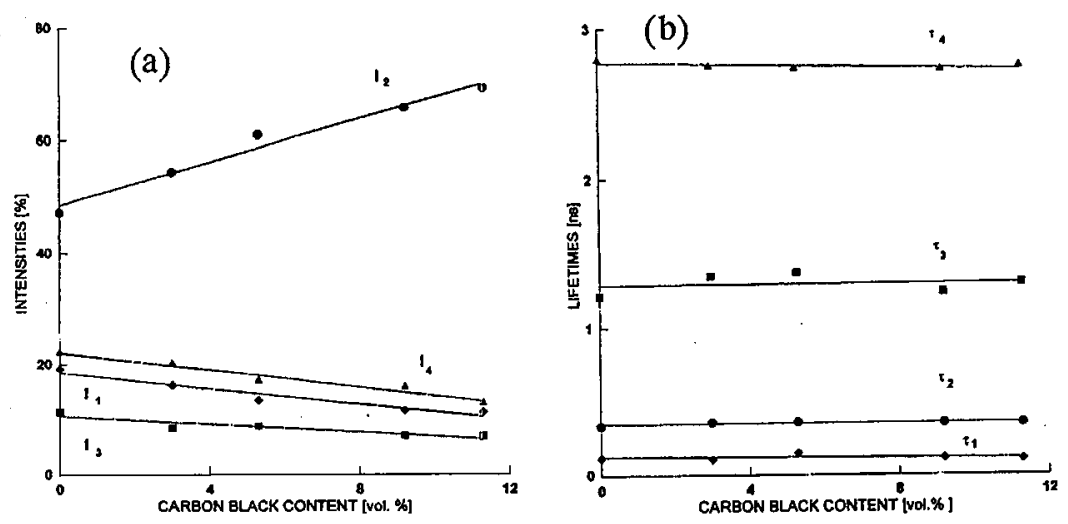

Fig. 3. Results of PAL measurements for PE-SAKAP composite: (a) intensities, (b) lifetimes. 


\section{Discussion}

The used fillers are of different structure as the values of the specific surface areas and pore volumes, given in Table, indicate. In a case of highly structured carbon black (more porous aggregates per unit weight) a contact between aggregates is attained easier at less content of carbon black. The results of the studies indicate that introduction of carbon black PRINTEX XE2 influences the most mechanical and electrical properties of the composites as well as the positron annihilation characteristics. In Fig. 4 and 5 the intensity $I_{2}$ and the sum $I_{3}+I_{4}$ vs. carbon black content are shown for all samples.

TABLE

The most important characteristics of the used fillers.

\begin{tabular}{l|c|c|c}
\hline \multicolumn{1}{c|}{ Properties } & PRINTEX XE2 & VULCAN XC-72 & SAKAP 6 \\
\hline Specific surface area & 950 & 280 & 200 \\
$\quad\left(\mathrm{~N}_{2}\right.$ adsorption, BET) $\left[\mathrm{m}^{2} / \mathrm{g}\right]$ & & & \\
Pore volume DBP $\left[\mathrm{cm}^{3} / 100 \mathrm{~g}\right]$ & 380 & 180 & 120 \\
Iodine absorption $[\mathrm{mg} / \mathrm{g}]$ & 1075 & 253 & $>200$ \\
$\mathrm{pH}$ value & 8 & 7.5 & 9 \\
Ash content [\%] & $<1$ & 1.5 & 1 \\
Mean particle diameter $[\mathrm{nm}]$ & 30 & 30 & 25
\end{tabular}
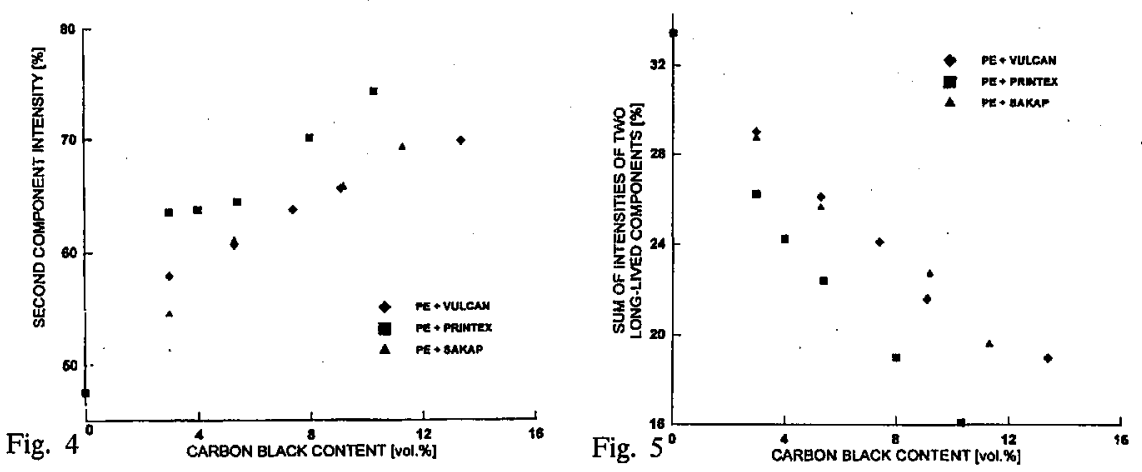

Fig. 4. Second component intensity $\left(I_{2}\right)$ vs. carbon black content.

Fig. 5. The sum of intensities of the two long-lived components $\left(I_{3}+I_{4}\right)$ vs. carbon black content.

The drop in intensities of all components ascribed to positronium $\left(I_{1}, I_{3}, I_{4}\right)$ observed after introduction of carbon blacks to polyethylene may result from both the absorption of positrons by carbon black and inhibition of positronium formation (values of lifetimes do not change nearly). Positronium is not formed in carbon blacks of which only one-component spectra are characteristic with the lifetime close to $360 \mathrm{ps}$ [4]. Thus the absorption of positrons in carbon black could 
explain the reduction of the intensities $I_{1}, I_{3}, I_{4}$. However the contribution of absorption of positrons in carbon blacks (estimated by us with the assumption of uniform distribution of carbon black particles in the polymer matrix and taking into account the volume content of carbon black in a composite) is smaller than the observed increase in $I_{2}$.

The inhibition of the positronium formation in carbon black-polyethylene samples is quite probable as it appears from the Doppler broadening of the annihilation line measured by us. The exemplary data given in Fig. 6 for the composites polyethylene-VULCAN prove it.

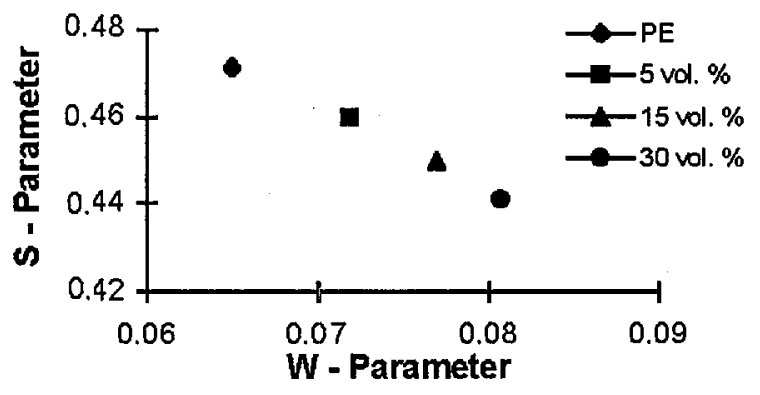

Fig. 6. $S$ - and $W$-parameters for PE-VULCAN composites.

Because of the dispersion of the used carbon blacks one should also take into account species present on their surfaces. The elemental analysis of a normal carbon black reveals there, in addition to carbon, small amounts of such elements as oxygen, hydrogen, nitrogen, and sulphur. Functional surface groups containing oxygen (carbonyl, carboxyl, pyrone, phenol, quinone, lactol, and others), that are chemically bound relatively tightly, were found by analysis [5]. It is known that such groups act as electron traps and thus decrease the conductivity [6]. One can expect that the groups are also attractive for electrons formed by the positrons in the final spurs and the same contribute to the inhibition of the positronium formation.

Apart from the positronium inhibition such groups could form the so-called "CT-complexes" with Ps as discussed in [7]. When supposing that the reduction of $I_{4}$ in composites results from the diffusion of $o$-Ps atoms to carbon blacks particles, dispersed in the polymer matrix, and quenching there one obtains the values of the Ps diffusion length equal to $14 \mathrm{~nm}, 18 \mathrm{~nm}$, and $21 \mathrm{~nm}$ in composites with SAKAP, VULCAN, and PRINTEX, correspondingly. Inhibition and quenching of positronium make the studies of changes of free volume impossible in the samples. In general, our results are in accordance with the ones obtained by others for carbon black-polymer composites [8-10].

\section{Acknowledgments}

This work was supported by University of Wrocław, grant No. 2016/IFD/98. 


\section{References}

[1] A. Pasternak, R. Poźniak, Raport ser. SPR no. 9/96, Instytut Technologii Organicznej i Tworzyw Sztucznych, Politechnika Wrocławska, Wrocław 1996, p. 4.

[2] Private communication from Dr. Jacek Pigłowski based on results of DSC measurements performed by him on the polyethylene sample.

[3] J. Kansy, Nucl. Instrum. Methods Phys. Res. A 374, 235 (1996).

[4] M. Dębowska, J. Girulska, to be published.

[5] "Carbon Black for Conductive Plastics", Technical Bulletin Pigments No. 69, Degussa Pigments Division, Frankfurt 1980.

[6] A.I. Medalia, in: "Carbon Black-Polymer Composites" Ed. E.K. Sichel, Marcel Dekker, New York 1982, p. 11.

[7] O.E. Mogensen, in: Positron Annihilation in Chemistry, Springer-Verlag, Berlin 1995 , p. $165,166$.

[8] D.H.D. West, V.J. McBrierty, C.F.G. Delaney, Appl. Phys. 18, 85 (1979).

[9] P.U. Arifov, S.N. Vasserman, S.A. Tishin, Positron Annihilation, Eds. P.C. Jain, R.M. Singru, K.P. Gopinathan, World Scientific, Singapore 1985, p. 787.

[10] M. Kostrzewa, Z. Michno, T. Majcherczyk, Acta Phys. Pol. A 88, 193 (1995). 